\title{
GOVERNANÇA METROPOLITANA: DEBATE E EXPERIÊNCIA REGIONAL DA REGIÃO METROPOLITANA DE MARINGÁ
}

\author{
METROPOLITAN GOVERNANCE: \\ DEBATE \\ AND \\ EXPERIENCE \\ OF \\ MARINGÁ METROPOLITAN REGION \\ Paulo Romano Reschilian ${ }^{1}$ \\ Agnes Yuri Uehara ${ }^{2}$
}

RESUMO: Maringá, município localizado no Norte do Paraná, diferencia-se de outros municípios brasileiros por seu planejamento urbano-regional caracterizado em sua organização espacial pelo modelo de cidade-jardim de inspiração inglesa. O artigo pretende abordar como foram constituídas as regiões metropolitanas brasileiras, partindo-se de um breve histórico da instituição da Região Metropolitana de Maringá e análises do processo de constituição dessa configuração regional. Verifica-se assim, que a cidade planejada reflete o "urbanismo à brasileira" e a urbanização desigual da maioria das nossas cidades, apresentando a realidade e os desafios inerentes à questão metropolitana.

Palavras-chave: planejamento urbano-regional; Região Metropolitana de Maringá; desafio metropolitano.

ABSTRACT: Maringá, a city located in Northern Paraná, differs from other Brazilian cities by its urban-regional planning, characterized by a spatial organization in the model of a garden city inspired in England. The article aims to address how the metropolitan regions of Brazil were constituted (federal and state institutions), by examining a brief history of the institution of Maringá metropolitan region and analyzing the process of establishing this regional settlement. Thus, this planned city reflects the "Brazilian urbanism" and the inequality of urbanization in most Brazilian cities, with the reality and challenges inherent in metropolitan issues.

Keywords: urban and regional planning; the Metropolitan Region of Maringá; metropolitan challenges.

\footnotetext{
${ }^{1}$ Docente da Univap. Doutor em Arquitetura e Urbanismo - USP.

E-mail: paromano@uol.com.br

${ }^{2}$ Mestranda em Planejamento Urbano e Regional - UNIVAP.

E-mail: agyuri@hotmail.com
} 


\section{INTRODUÇÃO}

As regiões metropolitanas brasileiras foram criadas a partir da Lei Complementar no 14/73, por Legislação Federal localizadas nas principais capitais brasileiras: São Paulo, Belo Horizonte, Porto Alegre, Recife, Salvador, Curitiba, Belém, Fortaleza. Logo no ano seguinte, foi instituída por meio da Lei Complementar no 20/74 a Região Metropolitana do Rio de Janeiro.

Com a Constituição de 1988 a instituição das regiões metropolitanas brasileiras passa para a competência da legislação a compor a esfera de interesses dos estados.

$\S 3^{0}$ - Os Estados poderão, mediante lei complementar, instituir regiões metropolitanas, aglomerações urbanas e microrregiões, constituídas por agrupamentos de municípios limítrofes, para integrar a organização, o planejamento e a execução de funções públicas de interesse comum

(CONSTITUIÇÃO

REPÚBLICA FEDERATIVA DO BRASIL, 2010).

Transcorridos mais de trinta anos, de acordo com o Observatório das Metrópoles (2011), o país tem hoje 37 Regiões Metropolitanas, além de três Regiões Integradas de Desenvolvimento (RIDES), somando 482 municípios, além de Distrito Federal, ou seja, $8,6 \%$ do total dos municípios brasileiros.

O Paraná possui três Regiões Metropolitanas: a Região Metropolitana de Curitiba, criada em 1973 pela citada Lei
Federal no 14/73; Região Metropolitana de Londrina e a Região Metropolitana de Maringá, ambas criadas no mesmo ano de 1998. Essas duas criadas por Lei Complementar Estadual no 81/98 e no 83/98 respectivamente, e possuem processos semelhantes de instituição.

Os municípios de Maringá e da região em estudo possuem duas morfologias regionais: a Associação do Setentrião Paranaense $^{3}$ (Amusep) criada em 1972 e composta por trinta municípios e a Região Metropolitana de Maringá criada pela Lei Estadual no 83/98, que atualmente é composta por vinte e cinco Municípios administrada pela Coordenação da Região Metropolitana de Maringá (COMEM).

Neste artigo, o tema metropolitano será objeto de análise - debate de repercussão nacional ${ }^{4}$ - fundamentando-se nas reflexões de Souza (2000); Klink (2010); Moura (2010) e Maricato (2011a).

A partir desse debate, pode-se verificar por meio das pesquisas bibliográficas e entrevistas realizadas com Ana Lúcia Rodrigues (OBSERVATÓRIO DAS METRÓPOLES, 2010), Renato Cardoso Machado (Coordenação da Região Metropolitana de Maringá, COMEM, 2010; Associação dos Municípios do Setentrião Paranaense, AMUSEP, 2011); William

${ }^{3}$ Segundo BERGOC (2003) o processo de formação de Associações de Municípios do Paraná teve início em 1969 e se trata de uma organização formal de municípios pela iniciativa do poder Executivo, com aprovação do Legislativo, em território contínuo, com a finalidade de resolver problemas comuns por meio de reivindicação e elaboração de planos e projetos.

4 Senadora Marta Suplicy (05/09/11) Seminário Brasil Metropolitano; Emplasa (28/09/11 a 30/09/11) Seminário FNEM SP; Comunicado IPEA no116 (13/10/2011); entre outros. 
Amadeu Izepão (Prefeitura Municipal de Paiçandu, 2011) e Fabíola Cordovil (professora da Universidade Estadual de Maringá, UEM, 2011) que grande parte das análises referentes à realidade nacional são também identificadas na Região Metropolitana de Maringá.

Tais análises evidenciam que os desafios de âmbito nacional e a realidade presente nessa região indicam caminhos que se abrem à discussão dos debates contemporâneos a respeito das metrópoles brasileiras.

\subsection{Formação da Região Metropolitana de Maringá}

Art. 21. O Estado instituirá, mediante lei complementar, regiões aglomerações urbanas e microrregiões, constituídas por agrupamentos de Municípios limítrofes, para integrar a organização, o planejamento e a execução de funções públicas de interesse comum, assegurandose a participação dos Municípios envolvidos e da sociedade civil organizada na gestão regional (PARANÁ, 1998).

De acordo com a Assembléia Legislativa do Estado do Paraná, Maringá é a cidade pólo da Região Metropolitana de Maringá, que foi criada através da Lei Complementar nำ 83/98, compondo-se inicialmente de oito municípios.

Atualmente a Região Metropolitana de Maringá, por meio da Lei Complementar $\mathrm{n}^{\circ}$ 127 de 17/02/2010 compõem vinte e cinco Municípios (Fig. 1), porém alguns destes não se integram efetivamente ao município pólo, um dos motivos da ausência da integração, destacam Fleury e Silva, Savi e Silva (2010), o ingresso indiscriminado de novas municipalidades na Região Metropolitana dificulta a sua implementação efetiva que, até o presente momento, não ocorreu.
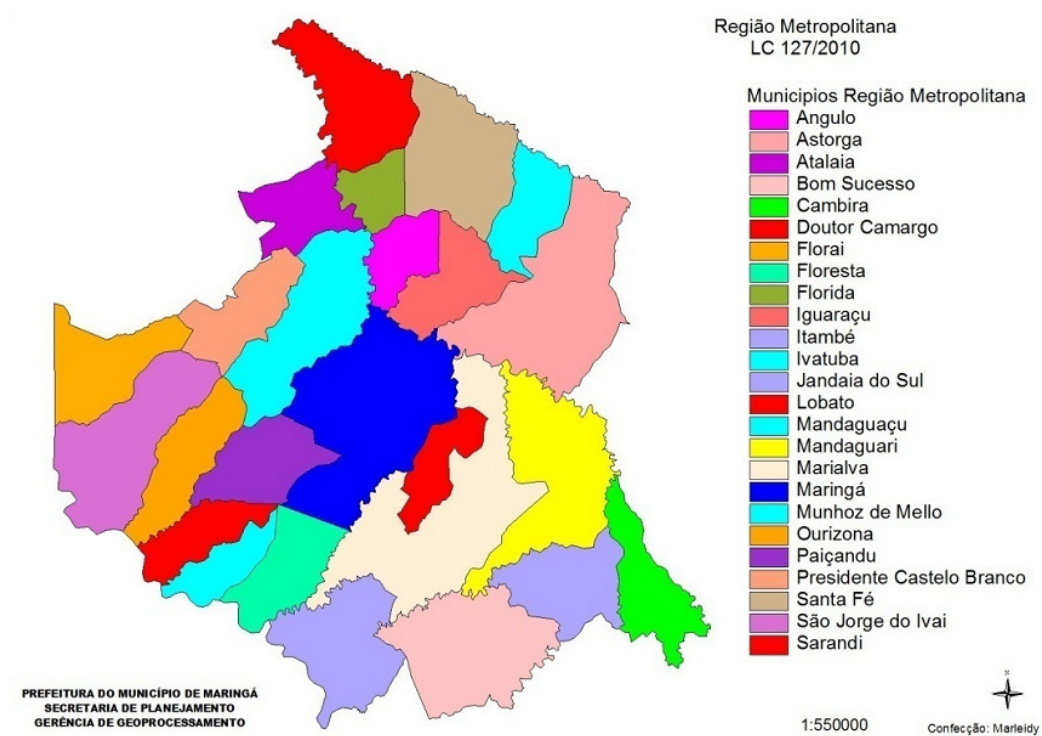

Fig. 1 - Municípios da Região Metropolitana de Maringá. Fonte: PREFEITURA DO MUNICÍPIO DE MARINGÁ, 2010. 
A Região Metropolitana de Maringá se identifica como espaço urbano de caráter não metropolitano na hierarquia metropolitana brasileira, expondo contradições políticas que envolvem a temática:

O neoconceito região metropolitana de caráter não metropolitano, ou seja, 'é o que não é', expõem de forma satisfatória as contradições que envolvem a temática, por denominarem institucionalmente certo número de municípios com centralidade restrita espacialmente, (...). Negá-las é extremamente complicado, pois, em geral, a mídia ligada às elites econômicas e políticas, além de estudiosos menos atentos ou de áreas de estudo que não se preocupam com a ocorrência ou não do processo de metropolização, acabam por confirmarem e (re) afirmarem, cotidianamente, institucionalidade das RMs, símbolo de poder das elites locais (MOTA, 2010, p. 61).

Por outro lado, é importante ressaltar, segundo consenso de pesquisadores da região norte do Paraná que um aglomerado urbano para ter uma espacialidade de região metropolitana, necessita possuir, no mínimo, uma relevante centralidade numa escala subnacional (macrorregião, por exemplo), isto é, possuir pelo menos uma metrópole, mono ou policentralizada, tendo sua relevância compreendida mais por sua situação geográfica do que pelas categorias demográficas (MOTA, 2010, p.62).

A partir dessa observação, pode-se afirmar que há em Maringá o centro de um aglomerado urbano com indícios de um processo de metropolização, mesmo sendo institucionalizado inicialmente por finalidades políticas.

Segundo as análises de participação do evento ANPUR ${ }^{5}$ (RIO DE JANEIRO, 2011), devido à complexidade da questão, verifica-se nas discussões a ausência na clareza para o reconhecimento e consenso desse processo denominado "metropolização".

Pode-se destacar no discurso de Ribeiro $^{6}$ (ANPUR, 2011) que a metrópole pode ser definida como um processo de conurbação, articulados para além da cidade e não mais por proximidade física, já que as mudanças de comunicação e mobilidade alteram os fluxos do território gerando dois processos que se pode destacar: a fragmentação e/ou unidade.

A questão central do processo de metropolização também pode ser visto segundo Paviani ${ }^{7}$ (ANPUR, 2011) no qual "ora se interessa integrar e ora excluir", ou ora se interessa a integração (ou a unidade) e por vezes a exclusão (fragmentação) das regiões, sobrepondo-se a questão geográfica e demográfica, refletindo nas

\footnotetext{
5 Associação Nacional de Pós-graduação e Pesquisa em Planejamento Urbano e Regional, evento que ocorreu em maio de 2011.

6 Discurso de Ribeiro, Luiz Cézar de Queiroz (IPPUR UFRJ). Mesa 5: Metrópole hoje: fragmentação/ integração. Rio de Janeiro: XIV Encontro Nacional da ANPUR, maio de 2011.

7 Discurso de Paviani, Aldo (UNB). Mesa 5: Metrópole hoje: fragmentação/ integração. Rio de Janeiro: XIV Encontro Nacional da ANPUR, maio de 2011.
} 
questões sociais de moradia, habitação e trabalho.

No ano de 2007 foi criado por intermédio da Secretaria do Estado do Paraná um órgão de gestão metropolitano: a Coordenação da Região Metropolitana de Maringá (COMEM), a qual propôs projetos de planejamento integrado a exemplo da integração do transporte das cidades da região até a cidade-pólo; a implementação de um trem de passageiros que serviria quinze cidades; projetos de moradias sociais com maior volume de investimentos; projetos de desenvolvimento local dentro da potencialidade de cada cidade, e diversos outros projetos.

Segundo dados obtidos a partir do Observatório das Metrópoles (2009) percebe-se que a Região Metropolitana de Maringá se constitui em um conjunto de municípios cujas características sócioeconômicas individuais resultam em espacialidades urbanas bastante diferenciadas umas das outras, sendo portanto, difícil a integração entre as mesmas.

Dentre as principais questões regionais, a desigualdade entre as municipalidades se destaca. A cidade pólo apresenta índices de renda, de incremento econômico, de organização institucional, de demografia, de habitação e de violência bastante diferenciados daqueles dos demais municípios (COMO ANDAM AS REGIÕES METROPOLITANAS, 2009, p. 185).

A falta de integração dos municípios dessas regiões analisadas tende a ser resultado das ações políticas efetuadas pelo governo estadual no momento que essas carregaram as raízes ideológicas dos princípios iniciais do planejamento "inspirados na teoria dos pólos de desenvolvimento, no qual o centro mais dinâmico das RM (no caso, as capitais) acabou adquirindo preponderância nas decisões e na absorção de investimentos (...) acentuando o modelo centro-periferia." (SCHASBERG; LOPES, 2011, p. 221).

A principal crítica que se percebe é explicada pela concorrência dos interesses locais e regionais instituídos pela Constituição de 1988 a qual não criou mecanismos de cooperação entre as três esferas de governo, conforme se verifica em Souza (2003) "as questões metropolitanas são tratadas ora como uma questão estadual, ora como uma questão meramente local" (SOUZA, 2003, p. 149).

Assim, o processo de metropolização do espaço urbano na região de Maringá se expressa, como em muitas cidades brasileiras, basicamente na expansão territorial de um aglomerado urbano. Tratase de uma seleção por determinadas áreas, fato que implica na exclusão de outras, como as cidades conurbadas de Sarandi, Maringá e Paiçandu com quais surgem novas centralidades, resultando no processo de segregação sócio espacial.

Assim, os instrumentos urbanísticos atribuídos as cidades por intermédio de Legislação municipal e do Plano Diretor deveriam assegurar o direito a cidades para obtenção de uma visão mais democrática aos interesses comuns a todos os cidadãos que nele habitam. 


\subsection{Desafios à questão metropolitana}

O entendimento do desafio remete à reflexão das condições sociais $e$ da qualidade de vida no meio urbano-regional, já que apesar de avanços econômicos e conquistas democráticas apresentados pelas cidades brasileiras nos últimos anos, como a criação do Ministério das Cidades (2003); O Programa de Aceleração do Crescimento, PAC $^{8}$ (2007); Programa Minha Casa Minha Vida (2009); entre outros programas especiais, pode-se concluir que "apesar dos avanços as cidades pioraram".

Entre esses programas, destaca-se a Política Nacional de Desenvolvimento Urbano (PNDU) do Governo Lula, com ênfase a Política Nacional de Regiões Metropolitanas, que segundo Maricato (2011a) a Secretaria Executiva do Ministério das Cidades havia contratado estudos que pretendiam informar 0 debate sobre a realidade urbana brasileira, assim como o 'estado das artes' das metrópoles brasileiras, diferentemente dos estudos apresentados na década de $70^{10}$.

Nesse período mais recente, para essa região, pode-se destacar três trabalhos importantes relativos ao avanço na discussão da temática, como mostra o trabalho de Moura et al (2008) no trabalho intitulado "Os 'vários Paranás' e o Planejamento do estado", o qual sintetiza a Política Estadual de Desenvolvimento

\footnotetext{
${ }^{8}$ De acordo com Losada (2010) O PAC é um programa de investimentos em infra-estrutura com foco nas regiões metropolitanas.

${ }^{9}$ Ver a respeito de MARICATO, E. (2011, p. 76).

${ }^{10}$ Segundo Losada (2010) a década de 70 foi um período de centralização financeira e autoritarismo político.
}

Urbano e Regional, encomendado pelo governo estadual; o Volume 7 do periódico Conjuntura Urbana, "Como andam as regiões metropolitanas: Curitiba e Maringá" (2009), assim como o estudo recente publicado no livro "Retratos da Região Metropolitana de Maringá: subsídios para elaboração de políticas públicas participativas" (2010), esses dois últimos trabalhos foram articulados por meio de pesquisadores do Observatório das Metrópoles.

Observa-se assim, segundo Klink (2010) que após um silêncio de duas décadas presenciamos a (re) emergência do tema metropolitano em outro cenário de produção e reprodução do espaço urbano e regional,

(...) num cenário de acumulação flexível, de descentralização das escalas territoriais de poder e de transformações no mercado de trabalho, as novas formas de mobilização e de governança dos territórios urbanos metropolitanos assumem um papel de destaque na discussão sobre o próprio modelo de desenvolvimento na sociedade contemporânea (KLINK, 2010, p. 9).

A política neoliberal praticada a partir do ano de 1980 desencadeou a fragmentação do espaço nacional mantendo a estrutura antiga do "atraso" característica das metrópoles brasileiras: "patrimonialismo, a privatização da esfera pública, o clientelismo e a política do favor, além da herança escravocrata e do desprestígio do trabalho." (MARICATO, 2011b, p. 8). 
A consequência para as metrópoles brasileiras desencadeou segundo essa autora,

(...) 0 desemprego, a competitividade, a guerra fiscal, o abandono de políticas sociais, como o transporte coletivo, as privatizações de serviços públicos, $\quad 0$ planejamento estratégico, o marketing urbano, entre outros, se combinaram a uma tradição histórica de falta de controle sobre o uso do solo e de segregação territorial e urbana (MARICATO, 2011b, p. 9).

Verificam-se assim, dois focos concentradores decorrentes dos problemas metropolitanos: "projetos de competitividade urbana, executados isoladamente por prefeitos neolocalistas em busca de atração das atividades econômicas" (KLINK, 2010, p. 9) e reforçada pelo fato do "padrão de investimentos em obras metropolitanas mostra a falta de integração entre as ações de cada município que compõem as metrópoles, e alguns governos estaduais apresentam apenas planos metropolitanos setoriais" (MARICATO, 2011b, p. 10).

Segundo análises, verifica-se que a discussão da região de Maringá pode ser compreendida em torno das seguintes questões: mobilidade pendular entre os municípios de Maringá, Sarandi e Paiçandu e o transporte metropolitano; geração de emprego e renda descentralizada; realidade de cidades com características rurais (Ângulo, Doutor Camargo e Presidente Castelo Branco) e no que tange a dificuldade de aplicação dos instrumentos do Estatuto da Cidade; falta de recursos e diretrizes orçamentárias; ausência de um plano metropolitano.

O primeiro desafio metropolitano que se coloca a Maringá e região é resolver o problema do transporte metropolitano. Podese concordar com Maricato (2011a) que de todos os fatores que contribuem para a condição de vida das metrópoles, o mais impactante é o modelo de mobilidade baseado na matriz rodoviarista, especialmente no automóvel, e o relativo desprezo pelo transporte coletivo.

Rodrigues (OBSERVATÓRIO DAS METRÓPOLES, 2011) alega a falta de prioridade do poder público ao transporte coletivo, afirmando que as pessoas optam pelo carro não só pelo preço, porque não é barato para mantê-lo. O sistema de transporte coletivo não assegura mobilidade que dê conta das necessidades dos usuários. Ainda observa que as moradias são levadas para áreas cada vez mais distantes.

Maringá concentra os principais postos de trabalho, educação e saúde, e verifica-se que a maioria da população se desloca para o município pólo, como pode se verificar na Tabela 1, a partir de dados do ano de 2004. 
Tabela 1 - População com 15 anos ou mais que trabalha e/ou estuda do aglomerado urbano de Maringá e a mobilidade pendular para outros Municípios e para a cidade pólo

\begin{tabular}{|c|c|c|c|c|c|c|}
\hline MUNICÍPIO & $\begin{array}{c}\text { Pop. com } \\
15 \text { anos } \\
\text { ou mais }\end{array}$ & $\begin{array}{l}\text { Pop. Que } \\
\text { estuda ou } \\
\text { trabalha no } \\
\text { próprio } \\
\text { Município }\end{array}$ & $\begin{array}{c}\text { Pop. Que se } \\
\text { desloca p/ } \\
\text { outros } \\
\text { Municípios }\end{array}$ & $\%$ & $\begin{array}{l}\text { Qtde de pessoas } \\
\text { que se dirigem a } \\
\text { cidade pólo } \\
\text { (Maringá) }\end{array}$ & $\%$ \\
\hline Maringá & 217.892 & 213.148 & 4.744 & 3,10 & - & - \\
\hline Paiçandu & 21.740 & 7.977 & 5.654 & 26,01 & 5.302 & 93,77 \\
\hline Sarandi & 50.298 & 18.158 & 14.467 & 28,76 & 13.315 & 92,03 \\
\hline
\end{tabular}

Fonte: MOTA, 2011, p. 58

Um dado importante a ser considerado é aquele que toca o sistema da educação. Segundo Veraldo et al (2010) Maringá ofertava até 2006, 125 cursos de graduação contando com 15 faculdades entre públicas e privadas, sendo "inegável o papel atrator da UEM nessa região, o que consolida um crescente movimento pendular das cidades do entorno na direção de Maringá" (VERALDO et al., 2010, p. 69).

Além do grave problema do impacto do automóvel como o trânsito e a demora nos tempos de viagens, comprova-se ainda a necessidade de interligar as áreas conurbadas dessa região por meio de transporte coletivo para os trabalhadores com apenas uma passagem. Conforme declaração, em entrevista do excoordenador da Região Metropolitana de Maringá, Renato Cardoso Machado ${ }^{11}$ (2010). Por suas palavras, essa integração está sendo discutida, foi um dos primeiros projetos a serem debatidos, porém ainda não se chegou a um consenso e uma solução.

\footnotetext{
${ }^{11}$ Quando foi realizada a entrevista em 02/12/2010, Renato Cardoso Machado era Coordenador da Coordenação da Região Metropolitana de Maringá; hoje ele responde pelo cargo de Coordenador Técnico pela Associação do Setentrião paranaense, Amusep.
}

Trata-se da ausência de uma política metropolitana eficaz. Segundo entrevista da Dra. Fabíola Cordovil ${ }^{12}$ (2011) verifica-se que nessa região encontram-se evidências da falta de política na questão dos transportes.

Além disso, esses problemas são agravados, pois a maioria dos administradores das grandes empresas prefere se instalar em Maringá. O citado dirigente Renato Cardoso Machado (2010) nota uma grande demanda dessas empresas, e decorrente desse fato, faltam terras para instalação destas no próprio Município de Maringá.

A consequência desse fator, de acordo com Rodrigues (2010) é o desemprego, uma vez que não existe uma política metropolitana de geração de emprego e renda que redirecione a instalação dessas empresas para outros municípios da região. Ainda decorrente desse fato, alguns municípios da região perdem população, ou possuem um pequeno adensamento populacional,

\footnotetext{
${ }^{12}$ Entrevista realizada em 29/07/2011, Fabíola Cordovil, professora do Curso de Arquitetura e Urbanismo da Universidade Estadual de Maringá.
} 
Para garantir o projeto cooperativo constitucional é necessário desenvolver soluções para enfrentar a acentuada heterogeneidade dos municípios brasileiros e a reduzida capacidade técnica, administrativa e financeira, especialmente dos municípios menores. [...] Outro fato que chama a atenção é o número de pequenos municípios, com menos de 10.000 habitantes (2670 unidades), que representam $48 \%$ do total dos municípios brasileiros. Esses pequenos municípios são justamente aqueles que apresentam escala inadequada para a prestação de determinados serviços públicos e mais dependem das transferências intergovernamentais para sua sustentabilidade (IBGE apud LOSADA, 2010, p. 271).

Segundo declaração do responsável pela Secretaria de Planejamento de Paiçandu, Willian Amadeu Izepão (2011), a ausência de parques industriais em Paiçandu faz com que toda a população seja obrigada a se deslocar diariamente em direção a Maringá para trabalhar.

Não é exagero lembrar os vínculos existentes entre 0 adensamento demográfico e as dinâmicas engendradas pelas políticas econômicas que, na atração de investimentos, provocam movimentos populacionais. Os efeitos concentradores e suas mazelas poderiam ser minimizados por políticas públicas regionais voltadas a incentivar a permanência da população nos pequenos municípios - sejam projetos de geração de emprego e renda, sejam transferências governamentais. Essa ordem de políticas não se restringe ao âmbito municipal, mas requer a ação articulada do Estado e da sociedade num esforço contínuo de planejamento e gestão regional que rompa a lógica perversa que caracteriza o desenvolvimento regional, desigual e socialmente injusto. No âmbito intraurbano, o modelo de ocupação adotado, especialmente nas áreas metropolitanas, induz à periferização da pobreza e ao abandono de grandes contingentes de população em territórios com baixa qualidade de vida urbana. É necessária, pois, a reversão desse modelo e da perversa lógica que desde sempre definiu 0 desenvolvimento urbano brasileiro, de forma a assegurar o direito à cidade para todos (OBSERVATÓRIO DAS METRÓPOLES, 2011).

O terceiro desafio é específico de três cidades dessa região: Ângulo, Doutor Camargo e Presidente Castelo Branco, que têm em sua característica concentração significativa de população nas áreas rurais, explicada pelas suas principais atividades econômicas como o plantio de soja, canade-açúcar, trigo e milho.

A modernização da agricultura, na esteira tanto da introdução de novas tecnologias quanto da 
disseminação de novas relações de produção, tem, nas últimas décadas produzindo a liberação e expulsão de enormes contingentes de trabalhadores agrícolas do campo. Um dos resultados foi um novo arranjo sócio-espacial das relações campo-cidade, com a conversão de muitos agricultores de colonos e camponeses em bóias-frias, isto é, em trabalhadores agrícolas, empregados como diaristas e mão-de-obra volante e pouco enraizada, que são, ao mesmo tempo, moradores urbanos, residentes nas periferias de cidades pequenas e médias (SOUZA, 2000, p. 319).

O Estatuto da Cidade estabelece que todos os municípios integrantes de Regiões metropolitanas são obrigados a ter seus Planos Diretores implementados no Município (LEI NÚMERO 10.257 ART. 41§ 50, 2001). Apesar disso, como se verifica em Galinari et al. (2010), determinados instrumentos do Estatuto da Cidade (parcelamento, edificação ou utilização compulsória, IPTU progressivo no tempo e desapropriação com pagamento em títulos) pouco foram aplicados nesses Municípios. $O$ panorama regional evidencia que essas três cidades apresentam uma amostra da "heterogeneidade das realidades que compõem a região e a inexistência de problemáticas comuns" (GALINARI et al., 2010, p. 144), sendo mais difícil a integração das mesmas.

A entrevista com o engenheiro Willian
Amadeu Izepão (2011), a qual contemplou a aplicação do Estatuto da Cidade no município de Paiçandu, evidencia que essa mesma situação pode ser atribuída a este município, pois o mesmo apresenta dois fatores marcantes que impossibilitam aplicação dos instrumentos urbanísticos do Estatuto das Cidades, entre eles o IPTU progressivo: baixa qualificação dos trabalhadores e baixa renda per capita.

Observam-se que para que todos esses desafios metropolitanos sejam discutidos e analisados de maneira "integrada" ${ }^{13}$, supõe-se a organização e sistematização de reuniões entre os prefeitos da região, somados a captação de recursos financeiros para implementação dos projetos e a execução de um plano metropolitano. Em entrevista, Rodrigues (2010) aponta como pequenas as estruturas físicas dos escritórios da Coordenação das Regiões Metropolitanas e muito pouco efetivas as ações praticadas por ela.

De acordo com a Lei Complementar 83 de instituição da Região Metropolitana de Maringá (1998) não se verifica a disponibilidade dos recursos orçamentários para desenvolvimento dos planos somente os recursos financeiros são provenientes às despesas de manutenção dos Conselhos Deliberativo e Consultivo ${ }^{14}$. A função desses Conselhos se resume em promoção, coordenação e sugestão de programas e projetos relativos à execução de serviços comuns.

No caso da Associação do Setentrião Paranaense, Amusep, segundo entrevista

${ }^{13} \mathrm{~A}$ integração foi proposta na Lei Complementar 83, de 17 de julho de 1998.

${ }^{14}$ Art. $2^{\circ}, \S^{\circ}{ }^{\circ}$ da Lei Complementar 83. 
com o responsável pela Coordenação técnica, Renato Cardoso Machado (2011) a situação dos Municípios em relação aos recursos financeiros é ainda mais difícil, pois dependem do apoio e participação de seus integrantes na Associação.

Importante o destaque do trabalho do Núcleo do Observatório das Metrópoles que está presente em Maringá pois, poderia por meio de trabalhos e pesquisas acadêmicas subsidiar a elaboração de políticas metropolitanas, porém, observa-se a falta de convergência entre a COMEM e o Observatório.

Alternativas a esse impasse podem ser recebidas por futuras alterações na legislação. Encontra-se em discussão, na Câmara Federal, 0 Projeto de Lei $n^{\circ}$ $3640 / 2004$, de autoria do deputado Walter Feldman, denominado Estatuto da Metrópole. Dentro desse Projeto de Lei os recursos para os municípios dessas regiões seriam recebidos por meio do Fundo Nacional de Planejamento e Informações Regionais Urbanas,

Fica o Poder Executivo Federal autorizado a constituir o Fundo Nacional de Planejamento e Informações Regionais Urbanas, aqui caracterizado como o instrumento institucional de caráter financeiro, com a finalidade de dar suporte ao planejamento integrado $e$ às ações conjuntas dele decorrentes no que se refere às funções públicas de interesse comum entre a União, os Estados, o Distrito Federal e os Municípios integrantes de regiões aglomerações

urbanas, microrregiões e regiões integradas de desenvolvimento (Rides) (ARTIGO 26, LEI NÚMERO 3640/2004, DE ESTATUTO DA METRÓPOLE).

Esse Projeto de Lei foi questionado por Moura e Firkowski (2008) com relação à captação e aplicação desses recursos financeiros, ainda que, de maneira geral, tal projeto seria restrito, excluído de sua relação a uma intensa rede de relações regionais (nessa mesma região, a Amusep estaria excluída dessa relação); a falta de clareza quanto aos objetivos $e$ as finalidades específicas, até mesmo quanto à classificação das unidades regionais referidas.

As especificidades do município de Maringá e região, a respeito do tema metropolitano, reforçam a análise de que a cidade planejada reflete o "urbanismo à brasileira" ${ }^{\prime 15}$ e reflete a urbanização desigual que a maioria das cidades brasileiras apresenta.

Decorridos mais de dez anos após sua instituição, a efetivação da integração de todos os municípios ainda é amplamente discutida por todos os agentes da produção do espaço social, que ainda produz a segregação e fragmentação do território. Supõe-se, então, que há muitos desafios a serem superados e muitos temas a serem estudados em busca de uma melhor solução para as nossas cidades.

\footnotetext{
${ }^{15}$ A expressão "urbanismo à Brasileira" faz parte do título do artigo de FERREIRA, J. S. W. São Paulo: cidade da intolerância, ou o urbanismo "à Brasileira". Estudos Avançados, São Paulo, v. 25, n. 71, p.7-22, jan./abr. 2011.
} 


\section{CONCLUSÃO E PERSPECTIVAS}

Na cidade de Maringá, assim como na maioria das cidades brasileiras, o planejamento urbano e o poder público se aliam aos interesses privados (mercado imobiliário e indústria da construção civil) para a reprodução do capital, dificultando o acesso da parcela marginalizada da população as áreas mais valorizadas.

Existem inúmeros trabalhos e estudos direcionados a Região Metropolitana de Maringá realizados por diversos grupos da sociedade e da população. Pode-se destacar 0 trabalho realizado pelo Observatório das Metrópoles em Maringá, sediado na Universidade Estadual de Maringá, que mostra que há muito a ser estudado e explorado no âmbito do planejamento urbano integrado sobre esta região.

O artigo apresenta a experiência da Região Metropolitana de Maringá de modo a trazer as reflexões aos estudos para outras morfologias regionais, como a emergência da criação da Região Metropolitana do Vale do Paraíba e Litoral Norte ${ }^{16}$, projeto que se encontra em elaboração e discussão.

Pode-se concluir que, de maneira geral, diversos fatores dificultam a integração dessas regiões.

O primeiro empecilho que se pode citar segundo Losada (2010) é a superposição de iniciativas em uma mesma

16 Último Encontro em São José dos Campos, reuniu pesquisadores na Universidade do Vale do Paraíba (01/12/2011) no Seminário intitulado: "Perspectivas de Planejamento Urbano e Regional: a região metropolitana em debate" a fim de discutir a instituição da Região Metropolitana do Vale do Paraíba e do Litoral Norte. área de atuação, com competências difusas e mal definidas, como na atuação da Comem e da Amusep que abrangem praticamente os mesmos municípios, atuando em um mesmo território.

Sobre o dispositivo constitucional das leis complementares existem algumas polêmicas, segundo Losada (2010) que também dificultam a integração: a concordância dos municípios em ser integrante de uma instância regional; ausência da participação do estado, ou seu papel neutro e o debate sobre a criação de uma entidade intermunicipal para reunião dos prefeitos dos municípios.

Quanto às Regiões Metropolitanas, há um problema concernente à sua natureza jurídica e à autonomia municipal dos municípios formadores daquela, uma vez que a Constituição Federal de 1988 apenas delegou ao Estadomembro a possibilidade de criar tais regiões, mas, em momento algum, concedeu a estas a condição de um ente federativo e nem de pessoa jurídica de Direito público de caráter político (SERRANO, 2009, p. 134).

O critério político para criação de uma Região Metropolitana é reforçado pela própria lei complementar, segundo Serrano (2009), pois trata de uma prerrogativa imputada ao Estado-membro, prevendo a possibilidade de tal criação quando assim entender necessário, "em estruturas 'teóricas' de paridade, vinculadas a fundos metropolitanos que não chegaram a existir, criados apenas no papel, ou que se 
tornaram figuras frágeis e não utilizadas" (IPEA, 2011, p. 19), assim como não prevêem a respectiva extinção, pois a lei permanece em vigor, desde que não seja destinada sua vigência temporária, até que outra a modifique ou a revogue.

"A fragmentação ocorre porque a gestão metropolitana apresenta-se de forma dispersa pelas legislações estaduais existentes no país e também porque não há legislação específica, no plano federal, que a oriente e regule." (IPEA, 2011, p. 8).

Além dos desafios institucionais e políticos para a gestão metropolitana, Moura (2010) aponta desafios financeiros, escalares, econômicos (sustentabilidade), sociais, ainda que o "maior desafio talvez seja o de tirar do papel." (MOURA, 2008, p. 159).

$\mathrm{Na}$ literatura sobre o planejamento urbano-regional e sobre processo de urbanização no Brasil encontram-se elementos para se planejar/pensar, cidades mais justas de modo a reduzir a exclusão e desigualdades socioespaciais/ambientais.

A observação da realidade urbana brasileira permite verificar que "a urbanização à brasileira" reproduziu inúmeras situações semelhantes às quais se pode analisar no município de Maringá e em sua "metropolização". A população de Maringá ocupa a periferia urbana e até interurbana, e, ainda que "planejada" não conseguiu conter todas as demandas sociais e por outro lado, nem a instituição de uma região metropolitana contribuiu para melhor distribuição dos recursos e integração dos municípios para solução dos problemas comuns.

\section{REFERÊNCIAS}

ANPUR. Anais do XIV Encontro Nacional da Anpur. Rio de Janeiro, 23 a 27 de maio de 2011. CD Room.

AMUSEP. ASSOCIAÇÃO DO SETENTRIÃO PARANAENSE. Perfil sócio-econômico do Norte do Paraná. Maringá, PR. Disponível em: http://www.amusep.com.br. Acesso em: 14 out. 2011.

BRASIL. Constituição Federal (1988). Brasília: Câmara dos Deputados, Coordenação de Publicações, 2010.

BRASIL. Lei número $\mathbf{1 0 . 2 5 7}$ de 10 de julho de 2001. Brasília, DF: Diário Oficial, 2001.

BRASIL. Projeto de Lei $n^{\circ} 3640 / 2004$. Estatuto da Metrópole, 2004. Disponível em: http://www.camara.gov.br. Acesso em: 14 out. 2011.

COMO ANDAM AS REGIÕES METROPOLITANAS: CURITIBA E MARINGÁ, Secretaria do Estado do Paraná, $2009 . \quad$ Disponível em: http://www.observatoriodasmetropoles.ufrj.br Nol7_como_andam_curitiba_maringa.pdf.

Acesso em: 14 out. 2011.

\section{COMEM. COORDENAÇÃO DA REGIÃO} METROPOLITANA DE MARINGÁ. Secretaria do Estado do Paraná, PR. Disponível em: http://www.desenvolvimentourbano.pr.gov.br. Acesso em: 14 out. 2011.

FERREIRA, J. S. W. São Paulo: cidade da intolerância, ou o urbanismo "à Brasileira". Estudos Avançados, São Paulo, v. 25, n. 71, p. 7-22, jan./abr. 2011.

FLEURY E SILVA, B.; SAVI, E.; SILVA, R. D.

A configuração socioespacial do aglomerado metyropolitano SarandiRevista Univap, São José dos Campos-SP, v. 17, n. 30, dez.2011. ISSN 2237-1753 
Maringá-Paíçandu a partir da moradia popular: da gênese a atualidade, 2010. Disponível em: http://web.observatoriodasmetropoles.net/do wnload/gthab/Sem_set2010/Beatriz_Natal_fi nal.pdf. Acesso em: 9 jun. 2011.

GALINARI, A. F. et al. Planos Diretores Participativos para pequenos municípios paranaenses: limites e possibilidades de implementação do Estatuto da Cidade. In: RODRIGUES, A. L.; TONELLA, C. Retratos da Região Metropolitana de Maringá: subsídio para elaboração de políticas públicas participativas. Maringá: Eduem, 2010. p. 133-191.

IBGE. Censo Demográfico 2010. Instituto Brasileiro de Geografia e Estatística. Disponível em: http://www.ibge.gov.br/home/default.php.

Acesso em: 9 jun. 2011.

KLINK, J. Introdução. In: KLINK, J. Governança das metrópoles: conceitos, experiências e perspectivas. São Paulo: Editora Annablume, 2010. p. 7-17.

LOSADA, P. R. O Comitê de articulação federativa e o desafio da governança metropolitana no Brasil. In: KLINK, J. Governança das metrópoles: conceitos, experiências e perspectivas. São Paulo: Editora Annablume, 2010. p. 259-257.

MARICATO, E. Metrópole, legislação e desigualdade. Estudos Avançados, São Paulo, v.17, n. 48, p.151-167, jan./abr. 2003.

MARICATO, E. O impasse da política urbana no Brasil. Petrópolis, RJ: Vozes, 2011a. 219p.

MARICATO, E. Metrópoles desgovernadas. Estudos Avançados, São
Paulo, v. 25, n. 71, p. 7-22, jan./abr. 2011b.

MOTA, A. A. O que é a Região Metropolitana de Maringá: os múltiplos recortes espaciais e institucionais relacionados à cidade de Maringá. In: RODRIGUES, A. L.; TONELLA, C. Retratos da Região Metropolitana de Maringá: subsídio para elaboração de políticas públicas participativas. Maringá: Eduem, 2010. p. 133-191.

MOURA, R. Dinâmicas territoriais recentes: rupturas ou manutenção de tendências? Cadernos Metrópole, n. 24, p. 467-489, jul/dez. 2010.

MOURA, R. et al. Os "vários Paranás" e o planejamento do estado. Cadernos Metrópole, n. 20, p. 141-163, 2008.

MOURA, R.; FIRKOWSKI, O. Estatuto da Metrópole - Contribuição ao debate, 2008. Disponível em: http://www.observatoriodasmetropoles.net. Acesso em: 13 out. 2011.

OBSERVATÓRIO DAS METRÓPOLES. Desafios contemporâneos na gestão das Regiões Metropolitanas. Comunicado do Ipea. Boletim, n. 116, 13 de outubro de 2011. Disponível: www.ipea.gov.br. Acesso em: 5 nov. 2011.

PARANÁ (Estado). Lei Complementar 83 17 de Julho de 1998. Curitiba, PR. Disponível:

http://www.legislacao.pr.gov.br/legislacao/list arAtosAno.do?action=exibir \&codAto=8563\& codltemAto $=81925 \# 81925$. Acesso em: 9 jun. 2011.

PARANA. Lei complementar n. 83 de julho de 1998. Curitiba (PR): Diário Oficial, 1998.

PREFEITURA MUNICIPAL DE MARINGÁ. 
Secretaria de Planejamento Urbano de Maringá, 2011. Mapas. CD-Room.

RODRIGUES, A. L.; TONELLA, C. Retratos da Região Metropolitana de Maringá: subsídio para elaboração de políticas públicas participativas. Maringá: Eduem, 2010.

SCHASBERG, B.; LOPES, A. O tema metropolitano nos Planos Diretores. In: SANTOS JUNIOR, O. A.; MONTANDON, D. T. Os Planos Diretores Municipais: PósEstatuto da Cidade. Rio de Janeiro: Letra Capital, 2011. p. 219-254.

SERRANO, P. $\quad$ E. A. P. Região Metropolitana e seu regime constitucional. São Paulo: Editora Verbatim, 2009. 248p.
SOUZA, M. L. de. Mudar a cidade: uma introdução crítica ao planejamento e à gestão urbanos. 4. ed. Rio de Janeiro: Bertrand Brasil, 2003. 556p.

SOUZA, M. L. de. O desafio metropolitano: um estudo sobre a problemática sócio espacial nas metrópoles brasileiras. Rio de Janeiro, RJ: Bertrand Brasil, 2000. 366 p.

VERALDO, I. et al. Movimento pendular de estudantes do ensino superior público na RMM: viajando para estudar na UEM. In: RODRIGUES, A. L.; TONELLA, C. Retratos da Região Metropolitana de Maringá: subsídio para elaboração de políticas públicas participativas. Maringá: Eduem, 2010. p. $67-90$ 